\title{
CIENCIAMATRIA
}

Revista Interdisciplinaria de Humanidades, Educación, Ciencia y Tecnología

Año VII. Vol. VII. N¹2. Enero - Junio. 2021

Hecho el depósito de ley: pp201602FA4721

ISSN-L: 2542-3029; ISSN: 2610-802X

Universidad Nacional Experimental Francisco de Miranda (UNEFM). Santa Ana de Coro. Venezuela

Andrés Leopoldo Cando-Morales; Juan Carlos Erazo-Álvarez; Juan Edmundo Álvarez-Gavilanes; José Alberto Rivera-Costales

\section{$\underline{\text { DOI } 10.35381 / \mathrm{cm} . v 7 i 12.445}$}

\section{La pandemia COVID- 19 en la micro empresa: Emprendimiento e Innovación}

The COVID 19 pandemic in micro-enterprises: Entrepreneurship and Innovation

\author{
Andrés Leopoldo Cando-Morales \\ alcandom49@est.ucacue.edu.ec \\ Universidad Católica de Cuenca, Cuenca \\ Ecuador \\ https://orcid.org/0000-0002-0597-5064 \\ Juan Carlos Erazo-Álvarez \\ jcerazo@ucacue.edu.ec \\ Universidad Católica de Cuenca, Cuenca \\ Ecuador \\ https://orcid.org/0000-0001-6480-2270 \\ Juan Edmundo Álvarez-Gavilanes \\ juan.alvarezg@ucacue.edu.ec \\ Universidad Católica de Cuenca, Cuenca \\ Ecuador \\ https://orcid.org/0000-0003-0978-3235 \\ José Alberto Rivera-Costales \\ jriverac@ucacue.edu.ec \\ Universidad Católica de Cuenca, Cuenca \\ Ecuador \\ https://orcid.org/0000-0001-9965-081X
}

Recibido: 01 de octubre de 2020

Aprobado: 15 de diciembre de 2020 


\author{
CIENCIAMATRIA \\ Revista Interdisciplinaria de Humanidades, Educación, Ciencia y Tecnología \\ Año VII. Vol. VII. N¹2. Enero - Junio. 2021 \\ Hecho el depósito de ley: pp201602FA4721 \\ ISSN-L: 2542-3029; ISSN: 2610-802X \\ Universidad Nacional Experimental Francisco de Miranda (UNEFM). Santa Ana de Coro. Venezuela \\ Andrés Leopoldo Cando-Morales; Juan Carlos Erazo-Álvarez; Juan Edmundo Álvarez-Gavilanes; \\ José Alberto Rivera-Costales
}

\title{
RESUMEN
}

La pandemia afecto drásticamente a la disminución de la economía de cada país, por lo que las empresas enfrentan diversos riesgos operacionales y de estrategia, desarrollando así la realización y aplicación de un plan estratégico, haciendo que las empresas deben innovar para sobrevivir y seguir siendo competitivos. El presente artículo busca conocer en qué medida afecto la pandemia a la micro empresa, conjuntamente con las pautas administrativas empleadas para sobrellevar la crisis presentada. La metodología aplicada fue de tipo descriptiva, analizando las diversas situaciones presentadas donde se detalla desde lo más general a lo especifico. Se evidenció que la innovación fue fundamental en la micro empresa durante la crisis sanitaria con ello una nueva experiencia administrativa para ser aplicados. El desarrollo de un plan estratégico, permitirá al administrador direccionar con excelencia.

Descriptores: Estudio de mercado; consumidor; comercio interno. (Palabras tomadas del Tesauro UNESCO).

\begin{abstract}
The pandemic drastically affected the decline of the economy of each country, so that companies face various operational and strategy risks, thus developing the realization and application of a strategic plan, making companies must innovate to survive and remain competitive. This article seeks to know to what extent the pandemic affected the microenterprise, together with the administrative guidelines used to cope with the crisis presented. The applied methodology was descriptive, analyzing the various situations presented where it is detailed from the most general to the specific. It was evidenced that innovation was fundamental in the micro-enterprise during the health crisis, thus a new administrative experience to be applied. The development of a strategic plan will allow the administrator to direct with excellence.
\end{abstract}

Descriptors: Market research; consumers; domestic trade. (Words taken from the UNESCO Thesaurus). 


\section{CIENCIAMATRIA}

Revista Interdisciplinaria de Humanidades, Educación, Ciencia y Tecnología

Año VII. Vol. VII. N¹2. Enero - Junio. 2021

Hecho el depósito de ley: pp201602FA4721

ISSN-L: 2542-3029; ISSN: 2610-802X

Universidad Nacional Experimental Francisco de Miranda (UNEFM). Santa Ana de Coro. Venezuela

Andrés Leopoldo Cando-Morales; Juan Carlos Erazo-Álvarez; Juan Edmundo Álvarez-Gavilanes; José Alberto Rivera-Costales

\section{INTRODUCCIÓN}

La sociedad está cursando por un momento difícil, con una constante trasformación, en el ámbito tecnológico, económico, y social, lo que ha llevado a las empresas adaptarse a los diferentes entornos, exigiendo cambios institucionales y organizativos, donde se permitirá brindar una respuesta acertada a las nuevas exigencias y retos que se plantean estas organizaciones (Palmer, 2008). Durante la pandemia Covid - 19 obligó los empresarios tuvieron que adaptarse a las nuevas medidas y protocolos tanto para los clientes y sus trabajadores lo que llevó a reinventar y adaptar diversas estrategias independientemente del tipo de empresa.

La presente pandemia sigue afectando a escala mundial desde su aparición en el año 2019, siendo una enfermedad alta mente contagiosa y de rápida expansión, estando derivada del grupo corona virus cataloga con el nombre la Covid - 19, siendo sus primeros reportes de contagios del mercado de mariscos de la ciudad de Wuhan, provincia de Hubei perteneciente a la República Popular China. La Organización Mundial de la Salud (OMS) con fecha 11 de marzo de 2020 denomina pandemia global, virus que se transfiere de persona a persona, por gotas salivales, se recomiendan como medida de prevención, el lavado frecuente de manos, el uso obligatorio de mascarilla cubriendo la boca y la nariz, además el auto aislamiento conjuntamente con el distanciamiento social y el seguimiento oportuno a personas sospechosas infectadas (Organización Mundial de la Salud, 2020).

Las empresas enfrentan diversos riesgos operacionales como estrategia lo que conlleva a la realización de un plan estratégico por el acontecimiento presentado a nivel mundial. Las micro empresas dependen del vivir diario y su liquidez es escasa, en su mayoría con deudas financieras a entidades bancarias. En el ámbito empresarial la formación para los emprendedores tiene que ver de gran importancia las universidades y las escuelas donde fomentan las habilidades individuales conjuntamente con el apoyo incondicional, por lo tanto, las universidades y escuelas donde vivimos en un mundo globalizado están sujetos 


\begin{abstract}
CIENCIAMATRIA
Revista Interdisciplinaria de Humanidades, Educación, Ciencia y Tecnología

Año VII. Vol. VII. N¹2. Enero - Junio. 2021

Hecho el depósito de ley: pp201602FA4721

ISSN-L: 2542-3029; ISSN: 2610-802X

Universidad Nacional Experimental Francisco de Miranda (UNEFM). Santa Ana de Coro. Venezuela

Andrés Leopoldo Cando-Morales; Juan Carlos Erazo-Álvarez; Juan Edmundo Álvarez-Gavilanes; José Alberto Rivera-Costales
\end{abstract}

a cambios, a mayor competitividad por lo que para estos se presentan como nuevos retos (Parra-Alvíz, Rubio-Guerrero, \& López-Posada, 2017).

En el Ecuador, donde se socializó los protocolos por los organismos de control de salud pública, cada empresa emplea las recomendaciones dadas y a su vez crea estrategias para subsistir y sobrellevar la crisis económica afectada por la pandemia (Gestion de Riesgos, 2020). Para la micro empresa es un panorama incierto sin políticas claras lo que ha llevado a implementar medidas administrativas, con la finalidad de servir prestando su servicio a la comunidad con el riesgo de disminuir sus ingresos o en lo peor de los casos él cierre de la micro empresa. Se seleccionada la categoría restaurante de la clasificación nacional de actividades económicas (CIIU Revisión 4.0), en la estructura esquemática C10 - Elaboración de productos alimenticios (Instituto Nacional De Estadística y Censos, INEC, 2012).

El objetivo de la actual investigación busca conocer en qué medida afecto la pandemia a la micro empresa, conjuntamente con las acciones administrativas empleadas para sobrellevar la crisis presentada.

\title{
Referencial Teórico
}

\section{La Covid-19, sus inicios, expansión y efectos en la económica de las empresas}

Públicamente, la Covid -19 brotó de una fuente animal, pero se ha propagado. Se explica la posibilidad del origen del virus se derive del murciélago, pero menciona que por la paralización de la indagación de la transmisión no se siguió avanzando al priorizar la investigación del contagio del virus a nivel mundial (Ramos, 2020).

El virus ataca directamente al sistema respiratorio, donde el virus se transfiere de persona a persona, se deriva de la familia de corona virus, siendo identificada e investigada por primera vez en la ciudad de Wuhan, país de china. Los síntomas suelen aparecer mediante los 2 primeros o 14 días, con un promedio de 5 días al ser expuestos al virus. Por el momento la evidencia limitada con la que se cuenta menciona que el virus puede 


\begin{abstract}
CIENCIAMATRIA
Revista Interdisciplinaria de Humanidades, Educación, Ciencia y Tecnología

Año VII. Vol. VII. N¹2. Enero - Junio. 2021

Hecho el depósito de ley: pp201602FA4721

ISSN-L: 2542-3029; ISSN: 2610-802X

Universidad Nacional Experimental Francisco de Miranda (UNEFM). Santa Ana de Coro. Venezuela

Andrés Leopoldo Cando-Morales; Juan Carlos Erazo-Álvarez; Juan Edmundo Álvarez-Gavilanes; José Alberto Rivera-Costales
\end{abstract}

transferirse de uno a dos días antes, de que el usuario presente síntomas, ya que el virus Covid-19 logra su cúspide más alta al final de etapa de incubación (Organización Mundial de la Salud, 2020).

Fuentes oficiales apuntan que es altamente contagioso al igual que su propagación, siendo la principal sintomatología: la presencia de fiebre, la tos, la dificultad al respirar, al igual la pérdida del olfato o del gusto (El Comercio, 2020). Por otro lado, los inconvenientes provocados por el virus hacen que numerosos pacientes presenten neumonía en ambos pulmones. Por ellos, la Covid - 19 sobresalta con una mayor mortalidad a aquellas personas de edad avanzada con dolencias crónicas y enfermedades del corazón, pulmón o inmunodeficientes (Organización Mundial de la Salud, 2020).

Ante tanta incertidumbre, desde el inicio de la pandemia, las instituciones sanitarias han asegurado que la organización mundial de la salud recomienda que para una mejor prevención es evitar aglomeraciones siendo estos las principales propagaciones de la Covid -19, de igual manera una cultura de higiene, evitando contacto con individuos enfermos, evitar el contacto con las manos en los ojos, nariz y la boca sin ser anteriormente desinfectadas las manos con el uso correcto del agua, el jabón y el gel antiséptico, el auto aislamiento conjuntamente con la notificación correspondiente a la unidad de salud de su localidad para el seguimiento oportuno, tomando las medidas del recubrimiento de nariz y boca, la limpieza y desinfección de todos los objetos, conjuntamente con la superficie que toca con frecuencia, el uso de guantes y mascarillas, siendo recomendaciones iniciales al estar solo para pacientes contagiados. Sin embargo, los especialistas han recomendado el uso integral de máscaras quirúrgicas, según estudios sobre la Influencia $\mathrm{H} 1 \mathrm{~N} 1$, se muestran que podrían ayudar a reducir la propagación del virus (Ramos, 2020).

Actualmente no existe un tratamiento específico, lo que ha llevado a mantener medidas terapéuticas, lo que significa que el paciente que porte el virus es aplacar las 


\begin{abstract}
CIENCIAMATRIA
Revista Interdisciplinaria de Humanidades, Educación, Ciencia y Tecnología

Año VII. Vol. VII. N¹2. Enero - Junio. 2021

Hecho el depósito de ley: pp201602FA4721

ISSN-L: 2542-3029; ISSN: 2610-802X

Universidad Nacional Experimental Francisco de Miranda (UNEFM). Santa Ana de Coro. Venezuela

Andrés Leopoldo Cando-Morales; Juan Carlos Erazo-Álvarez; Juan Edmundo Álvarez-Gavilanes; José Alberto Rivera-Costales
\end{abstract}

sintomatologías y conservar las funciones vitales, diferentes universidades a nivel mundial y países están en la búsqueda en el menor plazo posible de la vacuna (BBC NEWS, 2020).

Las primeras personas con síntomas de Covid-19, con fecha 8 de diciembre de 2019, según las fuentes oficiales administrativas e instituciones sanitarias, conjuntamente con medios oficiales de comunicación. El 20 de diciembre se define a esta enfermedad como neumonía de origen indocumentado, afligiendo por lo menos a setenta personas, en su mayoría proveniente del mercado de Wuhan. El 30 de diciembre de 2019, la organización de treinta médicos del Hospital Central de Wuhan, encargada por la doctora Ai Fen, informa a los medios del grupo de corona virus y su semejanza al síndrome respiratorio agudo grave (La Vanguardia, 2020).

El 1 de enero de 2020 es clausurado el mercado de Wuhan, se procede a dar seguimiento a todas las personas con sintomatologías prosiguiendo a su aislamiento, conjuntamente a más de cuatrocientas personas trabajadores de la salud Salud, Los primeros fallecidos ocurrieron dentro de los días 09 y 16 días del mes de enero de 2020, siendo personas de edad avanzada o mayor a la edad de setenta años (Organización Mundial de la Salud, 2020).

Durante el día 05 de enero de 2020 la Clínica de Sanidad Pública de Shanghái logra secuenciar el virus, permitiendo a la comunidad internacional científica el desarrollo de test y vacunas contra el virus. Durante el 20 de enero del mismo año, la Comisión de Salud de China confirma un nuevo corona virus determinando que se transmite de persona a persona (Reporteros sin Fronteras, 2020). Por la alta cantidad de personas infectadas, así como las muertes alrededor del mundo, siendo finales del mes de abril de 2020 con un aproximado de 2,5 millones de contagiados alrededor de todo el mundo (Jiménez, 2020).

La economía global por la Covid - 19 pone en situaciones complejas lo que es de suma importancia la creación de políticas claras sobre la base de la sanidad y la economía con 


\begin{abstract}
CIENCIAMATRIA
Revista Interdisciplinaria de Humanidades, Educación, Ciencia y Tecnología

Año VII. Vol. VII. N¹2. Enero - Junio. 2021

Hecho el depósito de ley: pp201602FA4721

ISSN-L: 2542-3029; ISSN: 2610-802X

Universidad Nacional Experimental Francisco de Miranda (UNEFM). Santa Ana de Coro. Venezuela

Andrés Leopoldo Cando-Morales; Juan Carlos Erazo-Álvarez; Juan Edmundo Álvarez-Gavilanes; José Alberto Rivera-Costales
\end{abstract}

apoyo de la cooperación internacional, donde los países asiáticos conjuntamente con el Pacifico donde se anuncia que tendrán un índice de crecimiento de $0,5 \%$ durante el año 2020, siendo el índice más bajo desde el año de 1967, en los países de Europa y de Asia central, se observa que tendrán una reducción del 4,7\% de su economía, los países de América Latina y el Caribe, siendo un panorama muy trágico con un porcentaje mucho más alto de recesión económica de 7,2\%, los países de Oriente Medio conjuntamente con los países del Norte de África con un retroceso económico de 4,2\%, Asia Meridional se reducirá un $2,7 \%$ y por último el país de África del sur de Sahara con una reducción de 2,8\% (Banco Mundial, 2020).

\title{
Los países frente al nuevo corona virus, la Covid- 2019
}

Siendo china, epicentro del virus su economía tuvo un declive drástico, estando en un crecimiento más del 10\% PIB, baja al 5.5\% (Cinco Días, 2020). Durante los primeros días del mes de marzo 2020, con un aproximado de 3000 fallecidos, no se inscriben nuevos contagios en la población de china, permitiendo declarar el final de la etapa de crisis, sin embargo, la prensa de países extranjeros exclama que existen nuevos casos en la ciudad de Wuhan, ocultados por el gobierno.

La revista Lancet con el apoyo de varios investigadores, perteneciente a la Universidad de Hong Kong, el estudio da un resultado de 230000 infectados hasta el pasado 20 de febrero, cuando el gobierno chino reporta 55000 contagios, sin embargo, la (OMS) inscribe un dato más elevado con un 82000 hasta el 23 de abril de 2020. Siendo un misterio los datos reales, desde el inicio del brote de la pandemia, así como el verdadero lugar, su origen y la cifra real de fallecidos (El Mundo, 2020).

En el país de Corea del Sur, donde se inscribió su primera persona, confirmando para Covid - 19, con fecha 20 de enero de 2020, la expansión fue elevada, ya siendo 20 de febrero se inscriben un total de 350 casos, y con fecha 7 de marzo se inscribe cerca de 7000 y con aproximadamente 50 fallecidos (El Diario, 2020). Por otro lado, en España la 


\section{CIENCIAMATRIA}

Revista Interdisciplinaria de Humanidades, Educación, Ciencia y Tecnología

Año VII. Vol. VII. N¹2. Enero - Junio. 2021

Hecho el depósito de ley: pp201602FA4721

ISSN-L: 2542-3029; ISSN: 2610-802X

Universidad Nacional Experimental Francisco de Miranda (UNEFM). Santa Ana de Coro. Venezuela

Andrés Leopoldo Cando-Morales; Juan Carlos Erazo-Álvarez; Juan Edmundo Álvarez-Gavilanes; José Alberto Rivera-Costales

expansión del virus fue rápida, siendo el primer caso positivo el 31 de enero de 2020, y ante la ausencia de medidas de bioseguridad, siendo así el segundo país con más casos confirmados y en fallecidos ocupando el tercer puesto (Directos, 2020).

En América del Norte, se inscribe el primer caso confirmado en Estados Unidos, con fecha de 21 de enero 2020, a un hombre de 35 años que viajo a China, con el fin de evitar su propagación se informa de manera inmediata a los países que conforman América del Norte, Central y el Caribe. En América del Sur se informa por primera el 26 de febrero de 2020 en el país de Brasil, en la ciudad de Sao Paulo, siendo uno de los países de América del Sur con más casos contagiados al igual que fallecidos (Noticias Telemundo, 2020). En Perú, los casos positivos para corona virus crece exponencialmente, con fecha 18 de agosto de 2020, se inscribe un total de 541493 casos confirmados y un total de 26481 fallecidos, siendo el segundo país de América del Sur con más casos Covid-19 (Comercio, 2020). A continuacion se evidencia el impacto de la pandemia en el crecimiento de PIB de America Latina.

Impacto de la pandemia del coronavirus en el crecimiento del PIB en algunos países de América Latina según datos de octubre de 2020

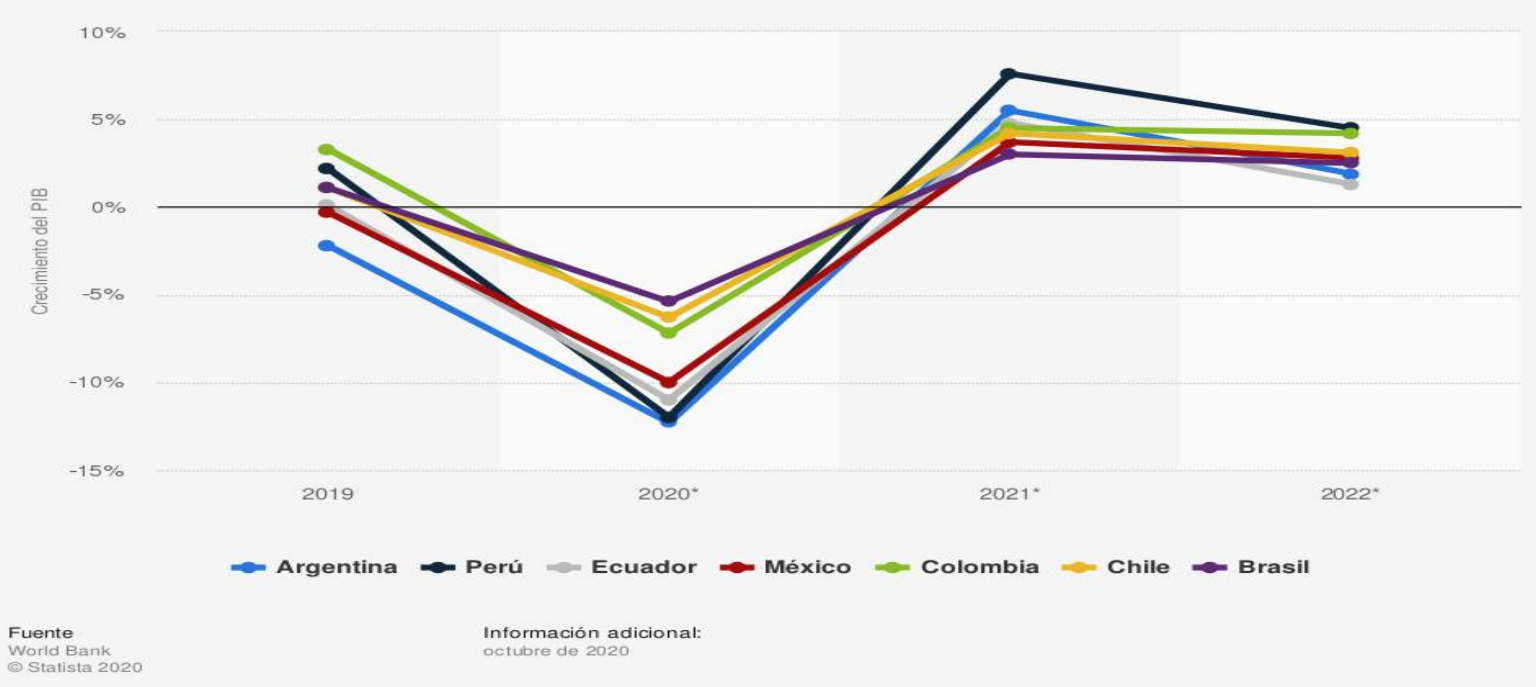

Figura 1. Impacto en el PIB de los países de América Latina.

Fuente: Pasquali (2020). 


\begin{abstract}
CIENCIAMATRIA
Revista Interdisciplinaria de Humanidades, Educación, Ciencia y Tecnología

Año VII. Vol. VII. N¹2. Enero - Junio. 2021

Hecho el depósito de ley: pp201602FA4721

ISSN-L: 2542-3029; ISSN: 2610-802X

Universidad Nacional Experimental Francisco de Miranda (UNEFM). Santa Ana de Coro. Venezuela

Andrés Leopoldo Cando-Morales; Juan Carlos Erazo-Álvarez; Juan Edmundo Álvarez-Gavilanes; José Alberto Rivera-Costales
\end{abstract}

En Ecuador registra un total 101751 casos confirmados para corona virus Covid- 19 y un total de 6083 fallecidos, ocupando el cuarto puesto de América del Sur con más casos Covid- 19 (Vistazo, 2020).

\title{
La micro empresa frente al corona virus la Covid - 19
}

La micro empresa conjuntamente con la innovación, siendo su principal principio de competitividad, formando la expansión y desarrollo económico (Naciones Unidas, 2014). La empresa debe tener la capacidad de innovación de forma continua, siendo uno de los objetivos de varias empresas, atrayendo sobresalientes beneficios para la organización. Sin embargo, la empresa que se encuentra superiormente gestionadas son empresas que incentivan a innovar y demostrando externamente a su competencia en la posición de liderazgo (Ballart, 2001).

La característica inseparable de la humanidad es innovar, especialmente al surgir la sociedad del conocimiento, en el que la creación y la comercialización de nuevas ideas, apuntando siempre a la superación, conjuntamente con la internacionalización de la empresa empleando sus ideas, métodos y las estructuras innovadoras (Shepherd, 2012). Ante la declaratoria del gobierno de suspensión de actividades por la emergencia sanitaria, causada por la pandemia del virus COVID- 19, la información confusa, ha dado lugar que muchos emprendedores tengan dudas de cómo actuar correctamente frente a sus trabajadores ante esta crisis (El Comercio, 2020).

Según (Martabit, 2008) el término estrategia proviene del ámbito militar donde la organización es asociada a la planificación de tareas donde el objetivo de alcanzar la meta que habitualmente es vencer a la competencia. En el contorno empresarial, teniendo en cuenta estas ideas, donde se especifica los objetivos, y se desarrolla planes de acción, estableciendo recursos para desempeñar y cumplir con los objetivos propuestos (Álvarez, et al., 2020). 


\section{CIENCIAMATRIA}

Revista Interdisciplinaria de Humanidades, Educación, Ciencia y Tecnología

Año VII. Vol. VII. N¹2. Enero - Junio. 2021

Hecho el depósito de ley: pp201602FA4721

ISSN-L: 2542-3029; ISSN: 2610-802X

Universidad Nacional Experimental Francisco de Miranda (UNEFM). Santa Ana de Coro. Venezuela

Andrés Leopoldo Cando-Morales; Juan Carlos Erazo-Álvarez; Juan Edmundo Álvarez-Gavilanes; José Alberto Rivera-Costales

La estrategia empresarial buscar crear un valor, a su vez la manera del que hacer y cómo hacerlo, definiendo los objetivos de la empresa, sus acciones, los recursos para ser empleados y cumplir con dichos objetivos (Conexión Esan, 2017). Según (Pümpin \& García, 1993), menciona que los entornos turbulentos, son oportunidades de la actuación empresarial, en segundo término, son naturalmente de riesgo. El éxito empresarial no se genera en procesos estables, sin rupturas, continuistas, sino que, al contrario, solo se genera éxito empresarial cuando la empresa se encuentra en una dinámica fuerte, como la propia estructura interna (Rivera, 2015).

La capacidad de adaptación en situaciones inestables se aloja en la capacidad de innovar y la creación para dar respuesta de coordinación y consecuentemente aprovechar las oportunidades (Scarone, 2005). El empresario es aquella persona que tiene la habilidad de crear mediante una idea, desarrolla el proyecto, lo prepara, lo arma, lo innova, una vez conformado, el empresario lo lanza al mercado generando fuentes de empleo y competitividad frente a otros mercados (Saínz, 2020).

El gerente general (CEO) influye en gran medida al trabajo óptimo, generalmente se ha demostrado que el gerente influye en la rentabilidad de la empresa con un porcentaje mínimo del $15 \%$ y un máximo del $20 \%$ (Tarziján, 2008). La innovación siendo cimiento fundamental frente a la competitividad, donde los emprendedores logran una superioridad competitiva enfrentando eficientemente al resto de competidores, a todo esto, se suma el trabajo competente o calificado, siendo estos los principales factores de excelencia comparativamente en las economías industriales (Castells \& Valls, 2003).

En el Libro de (Laviña, 2008), menciona que la innovación es el preámbulo de lo que es diferente, o significativamente renovado, de un producto, un bien o un servicio, conjuntamente de un diferente y distinto método que apoyara en si a la comercialización, apoyándose con distintos métodos de organización, con buenas practicas internas, una buena estructura de trabajo y sus relaciones exteriores (Erazo \& Narváez, 2020). El proceso de innovación desarrolla el capital humano, quienes manejan la información 


\begin{abstract}
CIENCIAMATRIA
Revista Interdisciplinaria de Humanidades, Educación, Ciencia y Tecnología

Año VII. Vol. VII. N¹2. Enero - Junio. 2021

Hecho el depósito de ley: pp201602FA4721

ISSN-L: 2542-3029; ISSN: 2610-802X

Universidad Nacional Experimental Francisco de Miranda (UNEFM). Santa Ana de Coro. Venezuela

Andrés Leopoldo Cando-Morales; Juan Carlos Erazo-Álvarez; Juan Edmundo Álvarez-Gavilanes; José Alberto Rivera-Costales
\end{abstract}

conjuntamente con el área de la informática y tecnología, dando paso a la competencia en los mercados, radicando la suma importancia de innovar envolviendo a los procesos de: servicio, producto, cambios administrativos y estructurales (Martínez, 2006).

Durante la última década, la informática las comunicaciones y el desarrollo creciente del servicio del Internet, el cual abre un nuevo mundo de oportunidades, muy distintas hace décadas atrás, las empresas para ser competitivos deben establecer el servicio de la tecnología lo que permitirá la interacción entre los clientes, socios, proveedores y colaboradores (López, Montes, \& Vázquez, 2007). Al observar desde otra perspectiva la calidad de la innovación en la tecnología se suma el incremento en la productividad, haciendo de suma importancia invertir en el mismo como el resto de países industrializados (Corma, 2011).

La innovación refiere que las actividades sistemáticas donde abarca el abanico de posibilidades como la creación de un nuevo producto, mejora de los procesos internos, cambios organizativos, estos deben contribuir a la eficiencia de la empresa, así mismo las propuestas de marketing y la comercialización que se convierte en la mejor o mayor producción de producto o servicio (Scarone, 2005).

La empresa para ser más competitiva debe plantear la innovación para sobrevivir y seguir siendo competitivo. Se debe ofrecer un bien, producto o servicio con nuevas prestaciones, con el menor costo de producción, crear fidelización con el cliente, la búsqueda de clientes potencial y ser más eficientes y atractivos frente a la competencia, esto se logra con el conocimiento empresarial, capital intelectual, el talento del recurso humano capaces de dar un mayor crecimiento en la cadena de valor (Manene, 2011). Dentro de la innovación de la empresa primeramente se debe implantar un cambio significativo o novedad dentro del mismo, mejorando la actividad o a su vez crear un proceso diferente, un nuevo hallazgo o a su vez una nueva manera de mejorar la organización (Rodríguez, 2017). 


\begin{abstract}
CIENCIAMATRIA
Revista Interdisciplinaria de Humanidades, Educación, Ciencia y Tecnología

Año VII. Vol. VII. N¹2. Enero - Junio. 2021

Hecho el depósito de ley: pp201602FA4721

ISSN-L: 2542-3029; ISSN: 2610-802X

Universidad Nacional Experimental Francisco de Miranda (UNEFM). Santa Ana de Coro. Venezuela

Andrés Leopoldo Cando-Morales; Juan Carlos Erazo-Álvarez; Juan Edmundo Álvarez-Gavilanes; José Alberto Rivera-Costales
\end{abstract}

El micro empresario debe estar preparado para el desarrollo de varias tareas al iniciar o estar ejecutando el negocio, con el desarrollo de destrezas y técnicas, esto dependerá del tipo de producto, bien o servicio que ofrezca, además se debe tener un conocimiento básico de comercialización, de producción, de financiamiento, el manejo de personal y de organización (Cuida tu Futuro, 2016).

\title{
MÉTODO
}

Metodológicamente se fundamentó en un tipo descriptiva con diseño de campo no experimental transversal, desarrollada en una población de 56 emprendedores en la categoría de restaurantes de la ciudad de Macas, provincia de Morona Santiago Ecuador, a quienes se les aplicó encuesta online mediante cuestionario de 12 preguntas de varias alternativas de respuestas siendo validado por juicio de expertos y cálculo de fiabilidad de Cronbach con resultado de 0,89 siendo confiable para su aplicación, la información recopilada fue procesada desde la estadística descriptiva con apoyo del programa Excel.

\section{RESULTADOS}

Consecuentemente a las encuestas dirigidas a los emprendedores que continúan con sus emprendimientos, de la categoría de restaurantes de la ciudad de Macas, provincia de Morona Santiago, se obtiene los siguientes resultados: Los emprendedores que continúan con el servicio se observa un significativo nivel de estudio superior con un total del $76,2 \%$, se puede deducir que estos emprendedores con conocimientos avanzados alcanzaron a sobrellevar su emprendimiento durante la pandemia. Del resultado de la investigación se observa que los emprendedores tienen a un familiar quien les apoya en el manejo del área administrativa con un resultado que el $42,9 \%$ y el $38,1 \%$ lo administran ellos mismos. Con un total de $57.1 \%$ cada dueño tomo la decisión de seguir prestando 


\section{CIENCIAMATRIA}

Revista Interdisciplinaria de Humanidades, Educación, Ciencia y Tecnología

Año VII. Vol. VII. N¹2. Enero - Junio. 2021

Hecho el depósito de ley: pp201602FA4721

ISSN-L: 2542-3029; ISSN: 2610-802X

Universidad Nacional Experimental Francisco de Miranda (UNEFM). Santa Ana de Coro. Venezuela

Andrés Leopoldo Cando-Morales; Juan Carlos Erazo-Álvarez; Juan Edmundo Álvarez-Gavilanes; José Alberto Rivera-Costales

su servicio con las normas de bioseguridad, en el nivel económico que afectó al emprendimiento con un $42,9 \%$.

Referente la decisión de mantener el personal durante la pandemia la COVID-19, nos da un resultado de $28,6 \%$ de Mantener al personal y con 23,8 de despedir al personal hasta retornar a la normalidad. Con un $66,7 \%$ durante la pandemia muchos emprendedores contaban con créditos en entidades bancarias, al seguir continuando con el emprendimiento los emprendedores optaron con un total de 33,3\% por innovar, seguido con un $23,8 \%$ en la capacidad de administrar de administrar su negocio. A la pregunta, si el emprendedor cuentan con un plan estratégico para situaciones de emergencia, con un total de 61,9 lo tienen en desarrollo.

Cabe indicar que el $38,1 \%$ las decisiones tomadas no fueron ni bueno ni malo, en lo que recae si durante la pandemia los emprendedores adquirieron nuevas experiencias administrativas dando un resultado de $57,1 \%$ seguido con un 38,1 que de cierta manera. Para los emprendedores la innovación en la parte informática es necesaria para la administración, con un total de 95,2\%. Cabe mencionar que los emprendedores, con un total de $76,2 \%$ aplicaran el marketing y publicidad, seguidos con la innovación y tecnología.

\section{PROPUESTA}

La presente investigación se basa en los resultados de las encuestas anticipadamente enviadas y su análisis respectivo es de suma importancia donde observó que varios emprendimientos al estar cerrados y otros parcialmente seguían prestando sus servicios durante la pandemia la COVID - 19, por lo tanto, se realiza la siguiente propuesta.

Dar a conocer las herramientas administrativas necesarias para su organización durante la crisis sanitaria que afectó a los micro emprendedores de la localidad, cabe mencionar que la investigación se enfoca en los emprendimientos de la clasificación nacional de actividades (CIIU Revisión 4.0) - Elaboración de productos alimenticios, en la categoría 
Universidad Nacional Experimental Francisco de Miranda (UNEFM). Santa Ana de Coro. Venezuela

Andrés Leopoldo Cando-Morales; Juan Carlos Erazo-Álvarez; Juan Edmundo Álvarez-Gavilanes; José Alberto Rivera-Costales

de restaurantes, a continuación, se da a conocer el esquema empleado en la presente investigación:

\section{Esquema pandemia COVID- 19 en la micro empresa; emprendimiento e innovación}

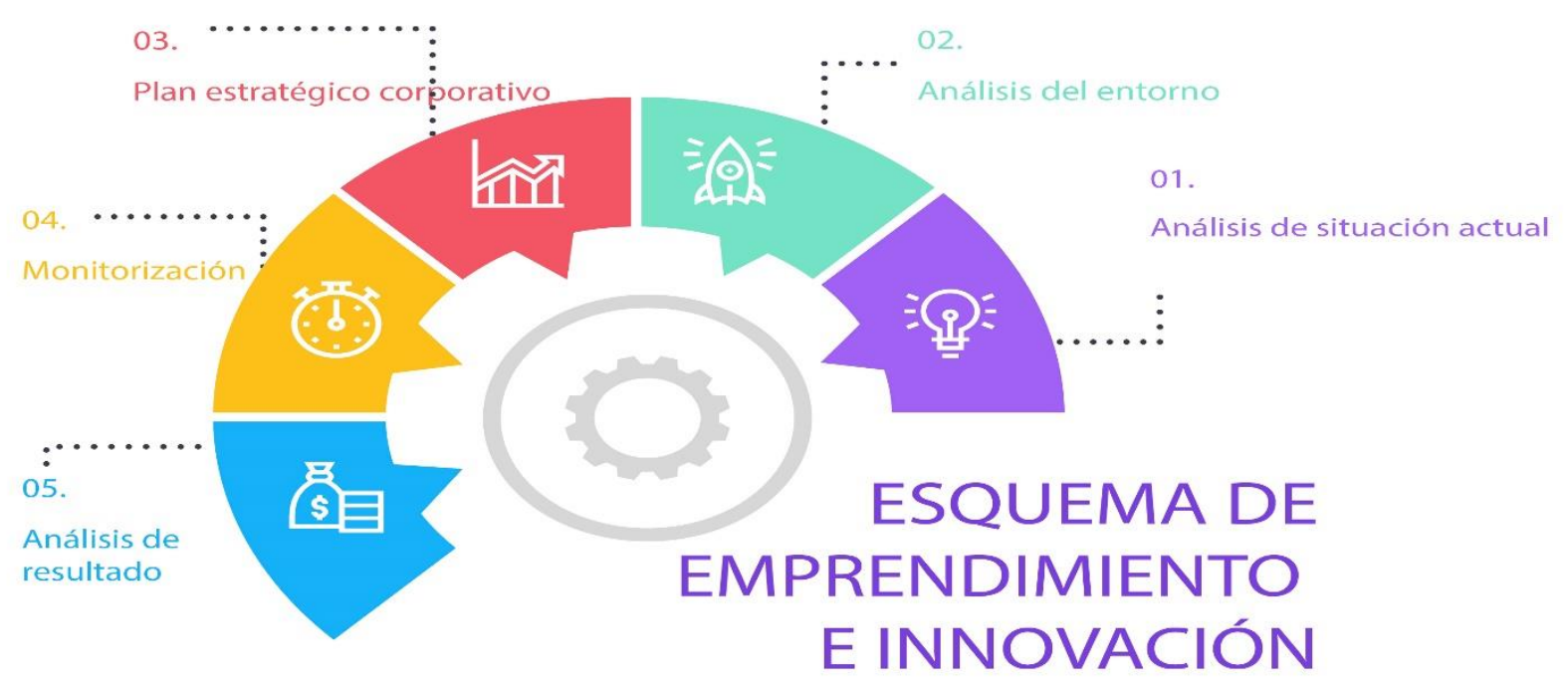

Figura 2. Esquema pandemia COVID- 19 en la micro empresa; emprendimiento e innovación.

Fuente: Elaboración propia.

\section{Análisis de estado de situación actual}

Para identificar la situación actual se procede apoyarse en una matriz FODA, donde el emprendedor identificará cada ítem y valorará el peso, la calificación y el peso ponderado donde el resultado en oportunidades - amenazas, si es mayor de 2.5, la empresa responde bien a las oportunidades y menor a 2.5 no se están aprovechando las oportunidades, en el resultado de fortalezas - debilidades un porcentaje por debajo a 2.5 es débil internamente y mayor a 2.5 la empresa mantiene una posición fuerte, información basada en las encuestas. 


\section{CIENCIAMATRIA}

Revista Interdisciplinaria de Humanidades, Educación, Ciencia y Tecnología

Año VII. Vol. VII. N¹2. Enero - Junio. 2021

Hecho el depósito de ley: pp201602FA4721

ISSN-L: 2542-3029; ISSN: 2610-802X

Universidad Nacional Experimental Francisco de Miranda (UNEFM). Santa Ana de Coro. Venezuela

Andrés Leopoldo Cando-Morales; Juan Carlos Erazo-Álvarez; Juan Edmundo Álvarez-Gavilanes; José Alberto Rivera-Costales

Tabla 1.

FODA, para el proceso de análisis de situación actual.

\begin{tabular}{|c|c|c|c|}
\hline & Peso & Calificación & $\begin{array}{c}\text { Peso } \\
\text { Ponderado }\end{array}$ \\
\hline \multicolumn{4}{|l|}{ OPORTUNIDADES (+) } \\
\hline Atender al mercado que todavía no se está haciendo & 0,08 & 4 & 0,32 \\
\hline $\begin{array}{l}\text { Mejoramiento de nuestros productos satisfaciendo las necesidad del } \\
\text { consumidor }\end{array}$ & 0,03 & 4 & 0,12 \\
\hline Existe la oportunidad de exportación & 0,06 & 1 & 0,06 \\
\hline La competencia se encuentra débil & 0,05 & 4 & 0,2 \\
\hline Nuestro mercado está en crecimiento & 0,02 & 3 & 0,06 \\
\hline Se puede crear nuevos productos al crearse mercados nuevos & 0,04 & 2 & 0,08 \\
\hline Mayor uso de nuestro productos & 0,07 & 4 & 0,28 \\
\hline Mejoramiento de costos & 0,05 & 3 & 0,15 \\
\hline Una mejor posición económica del país en los próximos años & 0,04 & 3 & 0,12 \\
\hline Los clientes tendrán mejor estabilidad económica & 0,05 & 4 & 0,2 \\
\hline \multicolumn{4}{|l|}{ AMENAZAS (-) } \\
\hline Ingreso al mercado la competencia extranjera con costos bajos & 0,04 & 4 & 0,16 \\
\hline Crece la venta de los productos sustitutos & 0,04 & 3 & 0,12 \\
\hline No crece el mercado según lo esperado & 0,05 & 3 & 0,15 \\
\hline $\begin{array}{l}\text { La costumbre del cliente está cambiando de forma negativa al hacer } \\
\text { uso de nuestros productos }\end{array}$ & 0,04 & 4 & 0,16 \\
\hline Se tiene un impacto negativo por el cambio demográfico & 0,06 & 3 & 0,18 \\
\hline Se modifican las directrices de la competencia de sus productos & 0,05 & 2 & 0,1 \\
\hline Precio bajo & 0,07 & 3 & 0,21 \\
\hline Concentración baja de clientes en el mercado & 0,05 & 4 & 0,2 \\
\hline Un mayor poder al negociación por parte de los proveedores & 0,06 & 3 & 0,18 \\
\hline Decaimiento de nuestro mercado & 0,05 & 2 & 0,1 \\
\hline Total & 1 & & 3,15 \\
\hline
\end{tabular}

\begin{tabular}{|l|r|r|r|}
\hline \multicolumn{1}{|c|}{ Factores críticos para el éxito } & Peso & Calificación & $\begin{array}{r}\text { Peso } \\
\text { Ponderado }\end{array}$ \\
\hline \multicolumn{1}{|c|}{ FORTALEZAS (+) } & & & 0 \\
\hline Se cuenta con un alta competitividad & 0,03 & 3 & 0,09 \\
\hline Existe los recursos económicos necesarios & 0,04 & 4 & 0,16 \\
\hline Dentro de la competencia somos lideres & 0,06 & 3 & 0,18 \\
\hline Contamos una excelente reputación con el proveedor & 0,07 & 4 & 0,28 \\
\hline Con los clientes se tiene una excelente reputación & 0,05 & 3 & 0,15 \\
\hline La estrategia de la empresa está bien definida & 0,04 & 3 & 0,12 \\
\hline Frente a la competencia nuestros productos son bajos & 0,05 & 4 & 0,2 \\
\hline Se cuenta con mejor calidad frente a resto de competencia & 0,03 & 2 & 0,06 \\
\hline Desarrollo de productos innovadores frente a la competencia & 0,05 & 3 & 0,15 \\
\hline $\begin{array}{l}\text { Existe la tecnología que se desacuerdo a la elaboración de nuestros } \\
\text { productos }\end{array}$ & 0,06 & & 0,12 \\
\hline \multicolumn{1}{|c|}{ DEBILIDADES (-) } & & & \\
\hline
\end{tabular}




\section{CIENCIAMATRIA}

Revista Interdisciplinaria de Humanidades, Educación, Ciencia y Tecnología

Año VII. Vol. VII. N¹2. Enero - Junio. 2021

Hecho el depósito de ley: pp201602FA4721

ISSN-L: 2542-3029; ISSN: 2610-802X

Universidad Nacional Experimental Francisco de Miranda (UNEFM). Santa Ana de Coro. Venezuela

Andrés Leopoldo Cando-Morales; Juan Carlos Erazo-Álvarez; Juan Edmundo Álvarez-Gavilanes; José Alberto Rivera-Costales

\begin{tabular}{|c|c|c|c|}
\hline La dirección no es clara & 0,04 & 2 & 0,08 \\
\hline Instalaciones obsoletas & 0,05 & 4 & 0,2 \\
\hline En el mercado se tiene una débil imagen & 0,04 & 3 & 0,12 \\
\hline El personal no es el adecuado & 0,06 & 4 & 0,24 \\
\hline No se cuenta con un gerente adecuado & 0,04 & 3 & 0,12 \\
\hline La línea de producto es muy estrecha & 0,07 & 4 & 0,28 \\
\hline No se cuenta con los recursos financieros & 0,06 & 3 & 0,18 \\
\hline La rentabilidad no es suficiente & 0,04 & 2 & 0,08 \\
\hline Frente a la competencia nuestros costos son mayores & 0,06 & 3 & 0,18 \\
\hline Los problema operativos son frecuentes & 0,06 & 2 & 0,12 \\
\hline Total & & & 3,11 \\
\hline
\end{tabular}

Fuente: Elaboración propia.

\section{Análisis del entorno}

Con la herramienta de análisis de factores políticos, económicos, sociales, tecnológicos, ecológico y legal (PESTEL), desarrollando cada punto de la matriz, el emprendedor visualizara su entorno que actualmente se prestando su servicio, logrando así un panorama más claro con el fin de elaborar un plan estratégico, a continuación, se detalla la matriz basada en el entorno que se maneja los restaurantes. 
CIENCIAMATRIA

Revista Interdisciplinaria de Humanidades, Educación, Ciencia y Tecnología

Año VII. Vol. VII. N¹2. Enero - Junio. 2021

Hecho el depósito de ley: pp201602FA4721

ISSN-L: 2542-3029; ISSN: 2610-802X

Universidad Nacional Experimental Francisco de Miranda (UNEFM). Santa Ana de Coro. Venezuela

Andrés Leopoldo Cando-Morales; Juan Carlos Erazo-Álvarez; Juan Edmundo Álvarez-Gavilanes; José Alberto Rivera-Costales

\section{Proceso para el análisis del entorno}

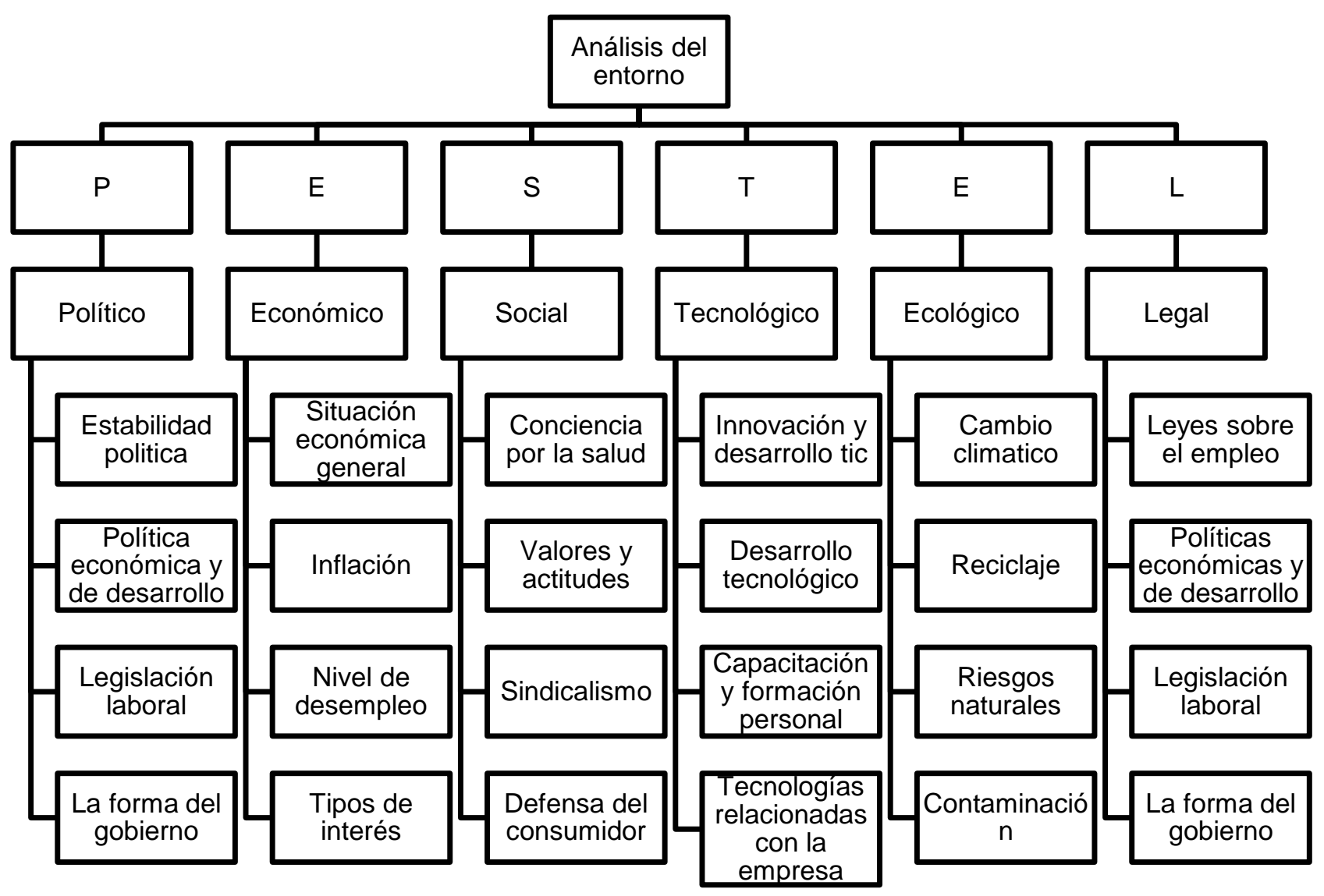

Figura 2. Proceso para el análisis del entorno.

Fuente: Elaboración propia. 
CIENCIAMATRIA

Revista Interdisciplinaria de Humanidades, Educación, Ciencia y Tecnología

Año VII. Vol. VII. N¹2. Enero - Junio. 2021

Hecho el depósito de ley: pp201602FA4721

ISSN-L: 2542-3029; ISSN: 2610-802X

Universidad Nacional Experimental Francisco de Miranda (UNEFM). Santa Ana de Coro. Venezuela

Andrés Leopoldo Cando-Morales; Juan Carlos Erazo-Álvarez; Juan Edmundo Álvarez-Gavilanes; José Alberto Rivera-Costales

\section{Plan estratégico corporativo}

Referente al plan estratégico se recomienda emplear un plan donde tendrán los siguientes puntos: la misión, visión y valores, siendo elementos fundamentales para la implementación del plan estratégico, en resumen, este concepto será hacia dónde va la empresa y a donde piensa llegar. La situación externa e interna, nos da una visión del lugar de donde nos encontramos ubicados, nuestro entorno y que alternativas estratégicas contamos. Los objetivos y estrategias, nos hace referencia de que objetivos, de cómo y cuándo estos serán alcanzados, de igual manera que estrategias serán empleadas para alcanzar estos objetivos. A continuación, se detalla los puntos fundamentales para el desarrollo del plan estratégico.

Tabla 2.

Proceso del plan estratégico corporativo.

\section{Proceso del plan estratégico corporativo}

\begin{tabular}{|l|l|}
\hline & \multicolumn{1}{|c|}{ Actividades a desarrollar } \\
\hline Misión & $\begin{array}{l}\text { Satisfacer la necesidades de los consumidores ofreciendo productos y servicios de } \\
\text { calidad. }\end{array}$ \\
\hline Visión & Para el 2021, tener 2 sucursales dentro de la provincia \\
\hline Valores & Compromiso, lealtad. \\
\hline Situación externa & Situación Política, económico, social, tecnológico \\
\hline Situación interna & $\begin{array}{l}\text { Recursos económicos, humanos, habilidades internas, fortalezas, capacidad de } \\
\text { adaptación. }\end{array}$ \\
\hline Objetivos & $\begin{array}{l}\text { Salvaguardar el liderazgo, ofrecer un excelente servicio, ser rentable, contribución } \\
\text { con el desarrollo del país. }\end{array}$ \\
\hline Estrategias & $\begin{array}{l}\text { Perseguir una ventaja competitiva a largo plazo, desarrollo de rol de competencia } \\
\text { organizativas. }\end{array}$ \\
\hline $\begin{array}{l}\text { Plan económico } \\
\text { financiero }\end{array}$ & $\begin{array}{l}\text { Verificar el monto del capital propio, necesidades financieras para el día a día, } \\
\text { verificar el volumen en ventas para ser rentables, tiempo para recuperar la } \\
\text { inversión. }\end{array}$ \\
\hline Planes de acción & $\begin{array}{l}\text { Plan de control comprueba durante su desarrollo como al final, ayuda a efectuar } \\
\text { con las estrategias planeadas y obtener el objetivo final del plan. }\end{array}$ \\
\hline
\end{tabular}

Fuente: Elaboración propia. 


\section{CIENCIAMATRIA}

Revista Interdisciplinaria de Humanidades, Educación, Ciencia y Tecnología

Año VII. Vol. VII. N¹2. Enero - Junio. 2021

Hecho el depósito de ley: pp201602FA4721

ISSN-L: 2542-3029; ISSN: 2610-802X

Universidad Nacional Experimental Francisco de Miranda (UNEFM). Santa Ana de Coro. Venezuela

Andrés Leopoldo Cando-Morales; Juan Carlos Erazo-Álvarez; Juan Edmundo Álvarez-Gavilanes; José Alberto Rivera-Costales

\section{Monitorización:}

El proceso de monitorización ayudará a obtener un mejor rendimiento de la organización, ya sea con el recurso humano, los procesos administrativos, las metas propuestas, las deficiencias encontradas y las demás dentro del área administrativa y operativa, lo que conlleva una ventaja frente a la competencia.

Tabla 3.

Proceso de monitorización.

Proceso de monitorización

\begin{tabular}{|l|c|c|c|c|}
\hline \multicolumn{1}{|c|}{ Descripción } & $\begin{array}{c}\text { Sin } \\
\text { iniciar }\end{array}$ & $\begin{array}{c}\text { En } \\
\text { desarrollo }\end{array}$ & Iniciado & Concluido \\
\hline $\begin{array}{l}\text { Revisión del avance del proyecto en los niveles de } \\
\text { actividad y de producto }\end{array}$ & & & $\mathrm{x}$ & \\
\hline Identificar la acción correctiva necesaria & & & $\mathrm{x}$ & \\
\hline Analizar la situación inicial & & & & $\mathrm{x}$ \\
\hline Identificar incidentes y buscar soluciones & & $\mathrm{x}$ & \\
\hline $\begin{array}{l}\text { Mantener las actividades del proyecto dentro del } \\
\text { cronograma }\end{array}$ & & $\mathrm{x}$ & \\
\hline Medir los procesos contra los resultados / productos & & $\mathrm{x}$ & & \\
\hline $\begin{array}{l}\text { Tomar decisiones sobre recursos humanos, } \\
\text { financieros y de materiales }\end{array}$ & & & $\mathrm{x}$ & \\
\hline Visitas al campo operacional & & $\mathrm{x}$ & & \\
\hline Informes & $\mathrm{x}$ & & & \\
\hline
\end{tabular}

Fuente: Elaboración propia. 
CIENCIAMATRIA

Revista Interdisciplinaria de Humanidades, Educación, Ciencia y Tecnología

Año VII. Vol. VII. N¹2. Enero - Junio. 2021

Hecho el depósito de ley: pp201602FA4721

ISSN-L: 2542-3029; ISSN: 2610-802X

Universidad Nacional Experimental Francisco de Miranda (UNEFM). Santa Ana de Coro. Venezuela

Andrés Leopoldo Cando-Morales; Juan Carlos Erazo-Álvarez; Juan Edmundo Álvarez-Gavilanes; José Alberto Rivera-Costales

\section{Análisis de resultado}

Para lograr analizar los resultados se debe definir reuniones periódicas con los miembros principales de cada área o proceso, donde deberán presentar, debatir y presentar los resultados alcanzados, apoyándose en análisis estadísticos, o la aplicación de encuestas dirigidas, finalmente el emprendedor, conjuntamente con los datos proporcionados y previamente analizados se dará a conocer al equipo sin modificar o cambiar el plan estratégico presentado a un inicio.

Tabla 4.

Análisis de resultado.

\begin{tabular}{|c|r|r|r|r|}
\hline & \multicolumn{1}{|c|}{$\begin{array}{c}\text { Tiempo } \\
\text { (semanas) }\end{array}$} & \multicolumn{1}{c|}{$\begin{array}{c}\text { Control } \\
\text { (semanas) }\end{array}$} & \multicolumn{1}{c|}{$\begin{array}{c}\text { En } \\
\text { desarrollo }\end{array}$} & \multicolumn{1}{c|}{ Terminado } \\
\hline Situación Actual & 5 & 2 & 3 & 5 \\
\hline Análisis del entorno & 10 & 4 & 5 & 10 \\
\hline Plan estratégico corporativo & 15 & 9 & 8 & 15 \\
\hline Monitorización & 20 & 15 & 10 & 20 \\
\hline
\end{tabular}

Fuente: Elaboración propia.

Una vez obtenido los datos se procede a realizar una grafico estadístico de dispersión, observando así el estado de análisis de resultado.

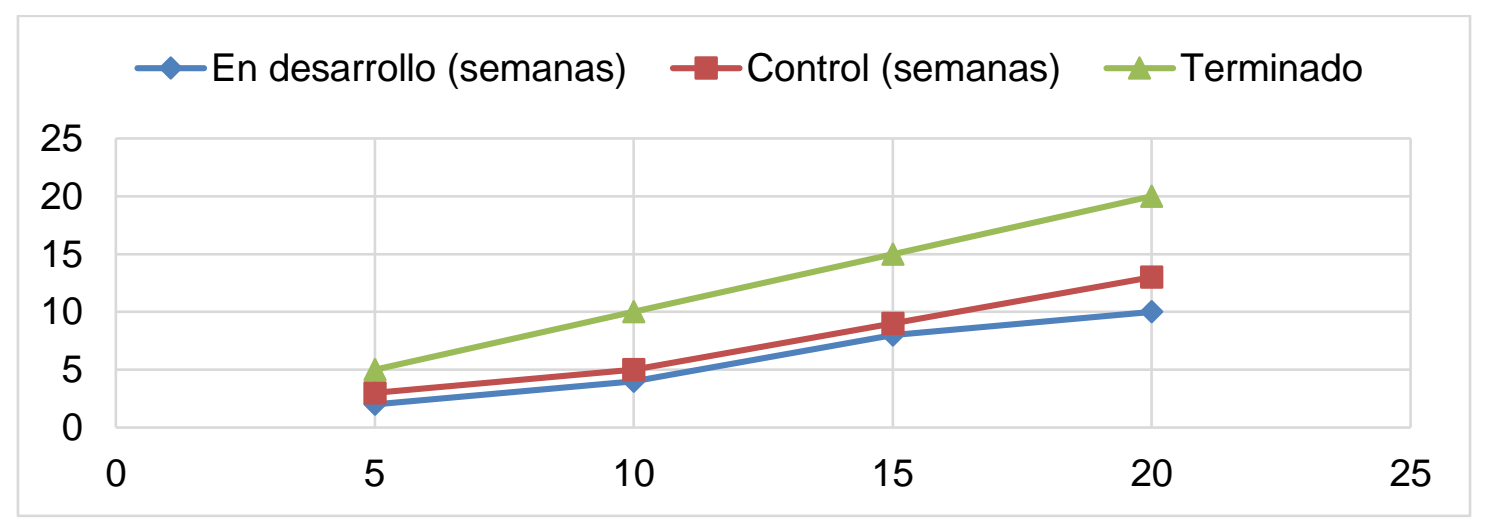

Figura 3. Nivel del análisis de resultado.

Fuente: Elaboración propia. 
CIENCIAMATRIA

Revista Interdisciplinaria de Humanidades, Educación, Ciencia y Tecnología

Año VII. Vol. VII. N¹2. Enero - Junio. 2021

Hecho el depósito de ley: pp201602FA4721

ISSN-L: 2542-3029; ISSN: 2610-802X

Universidad Nacional Experimental Francisco de Miranda (UNEFM). Santa Ana de Coro. Venezuela

Andrés Leopoldo Cando-Morales; Juan Carlos Erazo-Álvarez; Juan Edmundo Álvarez-Gavilanes; José Alberto Rivera-Costales

\section{CONCLUSIONES}

El desarrollo de un plan estratégico, permitirá al administrador direccionar con excelencia. Los conocimientos administrativos aplicando la innovación es de suma importancia al ser aplicados en el área de restaurantes con la finalidad de solventar sucesos emergentes como la pandemia.

Los emprendedores que siguieron prestando el servicio, contaban con conocimientos de tercer nivel, conocimientos adquiridos que formaron parte fundamental para sustentar la empresa.

El desarrollo de un plan estratégico, ayudara a direccionar de mejor manera la micro empresa

La competitividad hace que el emprendedor tome la iniciativa de innovar.

\section{REFERENCIAS CONSULTADAS}

Álvarez, C., Narváez, C., Erazo, J., \& Luna, K. (2020). Lógica difusa como herramienta de evaluación del portafolio de inversiones en el sector cooperativo del Ecuador [Fuzzy logic as an investment portfolio evaluation tool in Ecuador's cooperative sector] Revista Espacios, 41(36). Obtenido de https://n9.cl/bai6c

Ballart, X. (2001). Innovación en la gestion pública en la empresa privada [Innovation in public management in private companies]. Diaz de Santo.

Banco Mundial. (2020). La COVID-19 (coronavirus) hunde a la economía mundial en la peor recesión desde la Segunda Guerra Mundial. Obtenido de https://n9.cl/anhd

BBC NEWS. (2020). Coronavirus: cuáles son los 4 tratamientos que la OMS estudia para combatir el covid-19. Obtenido de https://n9.cl/2wr7y

Castells, E., \& Valls, J. (2003). Tecnología e innovación en la empresa [ Technology and innovation in the company]. Barcelona: UPC.

Cinco Días. (2020). Las claves de la epidemia de Wuhan y su impacto económico. Obtenido de https://n9.cl/q6myv 


\section{CIENCIAMATRIA}

Revista Interdisciplinaria de Humanidades, Educación, Ciencia y Tecnología

Año VII. Vol. VII. Nº12. Enero - Junio. 2021

Hecho el depósito de ley: pp201602FA4721

ISSN-L: 2542-3029; ISSN: 2610-802X

Universidad Nacional Experimental Francisco de Miranda (UNEFM). Santa Ana de Coro. Venezuela

Andrés Leopoldo Cando-Morales; Juan Carlos Erazo-Álvarez; Juan Edmundo Álvarez-Gavilanes; José Alberto Rivera-Costales

Comercio, E. (2020). Perú registra 6122 casos de covid-19 en las últimas 24 horas y supera los 600000 contagios. Obtenido de https://n9.cl/tcefs

Conexión Esan. (2017). ¿Qué es la estrategia empresarial y cómo ella se relaciona con el BSC? Obtenido de https://cutt.ly/QkzC7x4

Corma, F. (2011). Innovación, innovadores y empresa innovadora [Innovation, innovators and innovative companies]. Madrid: Ediciones Díaz de Santos.

Cuida tu Futuro. (2016). ¿Sabes qué es ser un microempresario? Aquí te enseñamos. Obtenido de https://cutt.ly/FkzBYPh

Directos. (2020). El mapa mundial del coronavirus: 105 millones de casos y más de 2,2 millones de muertos en todo el mundo Obtenido de https://n9.cl/ue6jl

El Comercio. (2020). 16 dudas sobre la jornada laboral en la emergencia. Obtenido de https://cutt.ly/dkzXyFk

El Comercio. (2020). Los pacientes covid-19 con síntomas de resfriado común o pérdida de olfato y gusto, los de mejor pronóstico. Obtenido de https://n9.cl/nktvf

El Diario. (2020). Corea del Sur eleva a 6.767 los contagiadas y a 44 muertos por coronavirus. Obtenido de https://n9.cl/ezxzz

El Mundo. (2020). Los casos de coronavirus en China podrían ser cuatro veces la cifra oficial. Obtenido de https://n9.cl/f14qy

Erazo, J. C., \& Narváez, C. I. (2020). La gestión del capital intelectual y su impacto en la efectividad organizacional de la industria de cuero y calzado en la Provincia de Tungurahua - Ecuador [The management of intellectual capital and its impact on the organizational effectiveness of the leather and footwear industry in the Province of Tungurahua - Ecuador]. Revista Espacios, 41(21), 254-271.

Gestion de Riesgos. (2020). Informe de situación COVID-19 Ecuador. Obtenido de https://n9.cl/f5tx

Instituto Nacional De Estadística y Censos (INEC, 2012). Clasificación Nacional de Actividades Económicas. Obtenido de https://n9.cl/el1w 


\section{CIENCIAMATRIA}

Revista Interdisciplinaria de Humanidades, Educación, Ciencia y Tecnología

Año VII. Vol. VII. N¹2. Enero - Junio. 2021

Hecho el depósito de ley: pp201602FA4721

ISSN-L: 2542-3029; ISSN: 2610-802X

Universidad Nacional Experimental Francisco de Miranda (UNEFM). Santa Ana de Coro. Venezuela

Andrés Leopoldo Cando-Morales; Juan Carlos Erazo-Álvarez; Juan Edmundo Álvarez-Gavilanes; José Alberto Rivera-Costales

Jiménez, C. M. (2020). La verdad de la pandemia: Quién ha sido y por qué [The Truth about the Pandemic: Who Has Been and Why]. Santiago: Mr (Ediciones Martinez Roca).

La Vanguardia. (2020). La misteriosa desaparición de Ai Fen, la doctora de Wuhan que alertó del brote de coronavirus. Obtenido de https://n9.cl/r9g7x

Laviña, J. d. (2008). Criterios e indicadores de la excelencia en la innovación empresarial [Criteria and indicators of excellence in business innovation]. Fundacion EOI: Graficas Muriel.

López, M., Montes, J., \& Vázquez, C. (2007). Cómo gestionar la innovación en las pymes [ How to manage innovation in pymes]. Coruña: Netbiblo.

Manene, L. M. (2011). El cliente: su valor, satisfacción, fidelización, retención y lealtad. Obtenido de https://cutt.ly/pkzBsrA

Martabit, J. T. (2008). Fundamentos de estrategia empresarial: Quinta edición [Fundamentals of Business Strategy: Fifth Edition]. Santiago, Chile: Ediciones.

Martínez, L. (2006). Gestión Del Cambio Y la Innovación en la Empresa [Change and Innovation Management in the Company]. Vigo: Ideaspropias.

Naciones Unidas. (2014). Ecuador un país emprendedor e innovador en el 2020. Obtenido de https://cutt.ly/tkzCWU6

Noticias Telemundo. (2020). El coronavirus llega a Estados Unidos: reportan el primer caso de la enfermedad cerca de Seattle. Obtenido de https://cutt.ly/4kzZ6rQ

Organización Mundial de la Salud. (2020). Brote de enfermedad por coronavirus (COVID19). Obtenido de https://n9.cl/g8wrg

Organización Mundial de la Salud. (2020). Nuevo coronavirus - China. Obtenido de https://n9.cl/x7zt

Organización Mundial de la Salud. (2020). Preguntas y respuestas sobre la enfermedad por coronavirus (COVID-19). Obtenido de https://n9.cl/nq49m

Palmer, D. S. (2008). Estrategias para enfrentar los retos de la globalización. Disponible en https://n9.cl/4tug 


\section{CIENCIAMATRIA}

Revista Interdisciplinaria de Humanidades, Educación, Ciencia y Tecnología

Año VII. Vol. VII. N¹2. Enero - Junio. 2021

Hecho el depósito de ley: pp201602FA4721

ISSN-L: 2542-3029; ISSN: 2610-802X

Universidad Nacional Experimental Francisco de Miranda (UNEFM). Santa Ana de Coro. Venezuela

Andrés Leopoldo Cando-Morales; Juan Carlos Erazo-Álvarez; Juan Edmundo Álvarez-Gavilanes; José Alberto Rivera-Costales

Parra-Alvíz, M., Rubio-Guerrero, G., \& López-Posada, L. M. (2017). Emprendimiento y creatividad [Entrepreneurship and creativity]. Bogota: Ecoe Ediciones.

Pasquali, M. (2020). Impacto de la pandemia del coronavirus en el crecimiento del PIB en algunos países de América Latina según datos de octubre de 2020. Obtenido de https://cutt.ly/ekzXTVH

Pümpin, C., \& García, S. (1993). Estrategia empresarial: cómo implementar la estrategia en la empresa [Business strategy: how to implement the strategy in the company]. Santiago: Díaz de Santos.

Ramos, J. S. (2020). Covid-19 hacia la nueva modalidad [Covid-19 towards the new modality]. Catargena: MalbecEdiciones.

Reporteros sin Fronteras. (2020). China - Coronavirus: "Si la prensa china fuera libre, el coronavirus no sería una pandemia", sostiene RSF. Obtenido de https://n9.cl/iy7p

Rivera, M. D. (2015). Universidad Carlos III de Madrid. Obtenido de https://cutt.ly/2kzVIkm

Rodríguez, V. (2017). La innovación y la internacionalización (Empresa y Administración) [Innovation and internationalization (Business and Administration)]. Madrid: Editex S.A.

Saínz, J. M. (2020). Emprendimiento en la práctica: Cómo las amenazas permiten reinventarse [Entrepreneurship in practice: How threats allow reinvention]. Madrid: Esic.

Scarone, C. (2005). La innovación en la empresa: la orientación al mercado como factor de éxito en el proceso de innovación en producto. Obtenido de https://cutt.ly/gkzVOXB

Shepherd, C. (2012). Administracíon de la innovación [Innovation Management]. Pearson Educación.

Tarziján, J. (2008). Fundamentos de estrategia empresarial: Quinta edición [Fundamentals of Business Strategy: Fifth Edition]. Santiago: Ediciones Universidad Católica de Chile.

Vistazo. (2020). Ascienden a 101.751 los contagios y 6.083 los muertos oficiales por COVID-19 en Ecuador. Obtenido de https://cutt.ly/RkzXKTy 


\section{CIENCIAMATRIA}

Revista Interdisciplinaria de Humanidades, Educación, Ciencia y Tecnología

Año VII. Vol. VII. Nº12. Enero - Junio. 2021

Hecho el depósito de ley: pp201602FA4721

ISSN-L: 2542-3029; ISSN: 2610-802X

Universidad Nacional Experimental Francisco de Miranda (UNEFM). Santa Ana de Coro. Venezuela

Andrés Leopoldo Cando-Morales; Juan Carlos Erazo-Álvarez; Juan Edmundo Álvarez-Gavilanes; José Alberto Rivera-Costales

(C2021 por los autores. Este artículo es de acceso abierto y distribuido según los términos y condiciones de la licencia Creative Commons Atribución-NoComercial-Compartirlgual 4.0 Internacional (CC BY-NC-SA 4.0) (https://creativecommons.org/licenses/by-nc-sa/4.0/). 